\title{
Lucia Nardo
}

\section{SOMETHING BROKE}

'Will AND Nic have split,' he says opening a bottle of red. The tsok of the emerging cork punctuates the announcement.

'What?' She stops, the crisp Cos snaps in her fingers and tumbles into the bowl. His eyes can't meet hers as he repeats what he'd said. It sounds unreal, like a rumour she shouldn't be listening to.

'But we had dinner with them last week.' She wears her Yet-Another-Thing look, reserved for when a changing world gnaws at her confidence. 'What happened?' She flops onto a chair and accepts a glass of wine with an unsteady hand.

'Dunno. Well, sort of-I know what he messaged me,' he says over the slosh of wine pouring into his glass. 'He says he never loved her.'

'It took him twenty years to decide?' Her brows arch.

He gives a resigned shrug. 'I've realised I never loved her. That's what it said. Christ! Is that how you announce your marriage is over?' He rubs his temple, where grey hairs signal Yet-Another-Thing.

She returns to the bench, her eyes riveted to a spot on the floor. 'Poor Nic. She never said anything was wrong.' Mechanically she continues making the salad; the knife slicing through tomatoes, bleeding the red insides onto the chopping board. 'Maybe she didn't know.'

'How could she not?' A note of disbelief in her voice. 'How could you not know your relationship is breaking?'

'Maybe she didn't want to know.'

The unsaid stretches taut between them, until she releases it with:

'Is there someone else?'The knife poised, ready to defend.

'He didn't say there was.'

Her eyes narrow, suspicious. 'Doesn't mean there isn't. So you did call and speak to him?'

Offset no. IO $\mid$ I7 
He swallows a mouthful of wine, sweet and calming. He nods.

'And?'Her expression asks for an explanation. Something definite, something that won't apply to them. Not to this world, their world.

'He didn't want to talk. Just sounded bloody tired.'

She swaps the knife for her wine glass. 'When's he moving out?'

'Nic's the one moving.'

'She is? But that house, she-I can't imagine her moving. Everything she loves is there.'

'Apparently not. He said she told him she was tired of being a couple.'

'Tired? Why would she be-?'

'Maybe they were both thinking it, just not saying it. One of them had to break the silence. Just happened to be him.'

He goes into the lounge room and flicks on the television, the volume shattering the quiet.

When dinner's simmering and the aroma of herbs create a familiar sense of home, her world resumes its usual shape. She joins him in the pre-dinner ritual of telly and talk, the plasma in the centre and their conversations off to the side.

She kicks off her shoes and puts her feet up. The polish on her toenails is chipped, and she tries to remember the last time she paid them attention. 'I should call her.'

'S'pose you should,' he says from his armchair, where he's settled with his belt loosened a notch and the remote in his hand.

'I'm not sure what to say.'

'You're kiddin'? You women talk about this stuff all the bloody time.'

'We talk about others in this situation.'

On her phone, she scrolls down the contacts. When she reaches 'Nic' she looks intently at the display before clattering the phone onto the coffee table. The clank forces him to stop channel surfing.

'What?'

'Probably a bad time to call.' She chews on her thumbnail.

'When's gunna be a good time?' he says and flips to A Current Affair.

Tonight she sets the table over a crisp cloth instead of the worn rattan placemats. From the cabinet where she keeps her Nice Things, Bohemia crystal wine glasses are extracted and the bluish film that dulls their sparkle washed away.

'Where'd you get these?' he asks, holding his glass to the light, to be rewarded with a shifting rainbow. 
She slides her eyes away, concentrating on straightening the cutlery.

'Will and Nic gave them to us when we got married. Remember?'

'Hon, I hardly remember the wedding.' There's laughter in his voice.

'That's not funny.'

'I'm sorry.' He reaches for her hand.

She pulls away. 'I just felt like using them.'

He sighs and asks if she needs help.

She turns her face away, shaking her head.

Her fork directs wilting lettuce around her plate, while he scrapes his plate clean. The television screen is visible from where they sit. The presenter drones at low volume.

'They never talk about what really matters,' she says, watching the deadpan anchorwoman.

'What do you mean?' He pours another wine, the deep red curves into the crystal glass and settles.

'The news. It's big stuff, but it doesn't really matter. Not like what's happening with Will and Nic.'

'The world goes on, hon. Anyway, that's only hurting them.'

'You don't get it, do you? It's happening to all of us,'she says, her tone layered with anxiety.

He shifts his weight slightly and sighs.

'Soon we'll lose them both as friends and-' her voice fades and she puts her fork down, as if the weight of it is suddenly too much.

'And what?'

'-And what we had with them, you know, as couples,' she finishes.

'Nah, we'll just stay in touch with them separately, he says, clattering his cutlery onto his empty plate and carrying it to the kitchen bench. 'Anyway, maybe it's what they both really want.'

She bites her lip and her finger circles the glass rim, while she forces herself to even her breathing.

At the sink, they tidy, dancing the steps of practiced domestic choreography. The sink's filled with warm water and lemon scented foam into which she lays the crystal glasses. Her touch is tender, baptismal. The silky water slips between her fingers and the bubbles cover the hint of age spots on her hands. Gently, she washes each rim and stem, before rinsing off the suds under running water. She checks each glass to the light and, satisfied there are no blemishes, she turns them upside down on a clean dishtowel. The plug comes out of the sink and the 
water drains away, until the last of it sucks into the pipes, like a long drawn-in breath. The remaining suds crackle and dull, popping into nothingness.

'Do you want me to dry those?' He points to the glasses.

'I'll fix them later.'

She rinses away the dying bubbles that scum up the sink.

Afterwards, having filled the evening with their parallel lives, they lie sideby-side, in bed, each knowing the other is awake.

'Did you ring Nic?'

'Not yet.' Her voice is small. 'How can she put everything in boxes and leave? You'd keep finding stuff, wouldn't you? Stuff you'd forgotten you had.'

'You should ring her.'

'I will,' she sniffs.

He's shared her bed long enough to know when she's checking tears.

'Hon, it's not happening to us.' He rubs her shoulder and feels her muscles tense. He rolls onto his back, staring at the ceiling, while she nurses the thought:

Would I see it coming?

The clock digits glow and mark each minute with a faint click. She fixes her open eyes to the numbers, trying to fend off her disquiet by making a mental list of all the things she's grateful for in a safe and predictable life.

Across the bed, he tosses, restless, uncomfortably avoiding the emotional territory she occupies. When he can't stand it anymore, he throws back the covers, and sits on the bed edge.

'What's up?' she responds to his sigh.

'I need some water.'

He turns on the hall light. For a few seconds, his silhouette frames in the doorway. It's changed; crept edgeways with the years. She's unexpectedly aware that she hadn't noticed while it was happening, only now, when it was done.

Vaguely alert to the noise of cupboards opening and closing and water running, she closes her eyes, relaxing into the sound of the usual.

A thump and an ear-splitting shatter, force her eyes open.

He swears and her heart picks up its beat.

She leans up on one elbow, squinting into the lighted doorway, listening to his mumbled curses, 'Everything okay?' Her voice pitches high.

'Just broke something,' he calls back.

There's nothing more to be explained. She knows the splintered fragments are impossible to reassemble. The tinkle of glass being swept into a dustpan is 
followed the clunk of the kitchen tidy lid, relegated to the unwanted.

Face pressed into the pillow, she cries. Her question gathers in clouds of doubt.

Do you ever see it coming?

He slides back into bed and pulls the covers close to his face. She waits for his rhythmic breathing to give her own a pattern to follow. She edges closer to him, feels the warmth of his body. Moulding her shape to his, breathing in his scent, attunes her ear to the hum of household appliances, the murmuring night sounds of the world outside her window_-sporadic traffic and distant dogs. Sleep comes slowly, weaving its way through the repeating whisper in her head.

Do you ever hear it breaking? 